\title{
A contaminação como potência no teatro/ performance: problematizações em torno do espectador na pós-modernidade
}

The contamination as potency in theater/performance: questioning about the spectator in postmodernit

Cecilia Lauritzen Jácome Campos ${ }^{1}$ 


\section{Resumo}

O artigo discute os lugares do espectador na cena contemporânea, a partir do estímulo à participação que caracteriza determinadas propostas teatrais recentes de cunho performativo. Com base nos escritos do teórico Hans-Ulrich Gumbrecht, aponta-se a produção de sentido como fenômeno inevitável do ato de leitura no intuito de encontrar possíveis modos de resistência. Em paralelo, discute-se a contaminação atual entre as linguagens artísticas, questionando sua efetiva potência relacional. A partir do relato da vivência do espetáculo Bivouac do grupo francês Genérik Vapeur, destaca-se a itinerância pela cidade como uma possibilidade para pensar a eficácia da relação espectador-espetáculo. Discute-se, igualmente, a questão da complexidade do trânsito entre territórios, o que gera reflexões em torno da disponibilidade dos sujeitos e dos níveis de envolvimento do espectador frente à cena teatral contemporânea.

Palavras-Chave: pós-modernidade; contaminação; teatro; performance; recepção.

\section{Abstract}

The article discusses the spectator's places in the contemporary scene, from the stimulus to participation that characterized some recent performative theatrical proposals. Based on the theoretical writings of Hans-Ulrich Gumbrecht, points to the production of meaning as an inevitable phenomenon of the act of reading in order to find possible ways of resistance. In parallel, discusses the current contamination between artistic languages, questioning its effective relational power. From the account of the experience Bivouac of the french group Generik Vapeur, stands out the itinerancy through the city as a possibility to think about the effectiveness of the spectator-spectacle relationship. Also discusses the issue of the complexity of transit between territories, which creates reflections on the availability of subjects and about the engagement levels of the spectator facing the contemporary theater scene.

Keywords: postmodernity; contamination; theatre; performance; reception

ISSN: 1808-3129

${ }^{1}$ Bacharel em Interpretação Teatral pela Universidade Federal da Paraíba. Mestre em Artes Cênicas pela Universidade Federal do Rio Grande do Sul e Doutoranda em Teatro pela Universidade do Estado de Santa Catarina. ceci.lauritzen@gmail.com 


\section{Introdução}

A contaminação entre linguagens que permeia a produção teatral recente traduz-se como característica determinante dos processos de recepção da performance e do teatro contemporâneos. Ao questionar os lugares do público na cena recente frente à demanda da participação, o artigo relativiza a contaminação como potência, problematizando o ato de leitura requisitado pelas propostas teatrais performáticas. Para discutir tais processos o artigo toma como base a investigação sobre a pós-modernidade realizada por Fredric Jameson, bem como se aproxima do debate sobre a produção de sentido e presença proposto pelo linguista Hans-Ulrich Gumbrecht.

O intuito do trabalho é lançar provocações e discutir acerca das práticas performativas contemporâneas, cujas premissas transitam muito pela permissividade e pelo experimentalismo, debruçando-se ainda insatisfatoriamente sobre a análise das reais reverberações dos processos criativos. É importante frisar que não se trata de defender uma visão tradicionalista da arte, mas, sobretudo, de ponderar os discursos totalizantes em torno do contemporâneo na arte. Como meio de elucidar as provocações colocadas, realiza-se um relato da vivência do espetáculo Bivouac do grupo de teatro de rua francês Genérik Vapeur, traçando reflexões sobre a noção de território (Gilles Deleuze) em relação à experiência do espectador na cena performativa.

\section{Pós-moderno, breve contextualização}

Para a discussão acerca do pós-moderno toma-se como base os estudos do crítico norte-americano Fredric Jameson. Estudar tal fenômeno implica num modo de pensar que resiste às definições, aos encaixes das disciplinas, aos conceitos. Por esse motivo, Jameson (2006) recorre à obra de Michel Foucault como exemplo do "modelo" pós-moderno que instaura o chamado "discurso teórico", já que sobre a mesma pode-se lançar a seguinte questão: trata-se de filosofia, história, teoria social ou ciência política? O conflito da resposta que pode corresponder a todas alternativas representa de forma fiel um traço desse fenômeno que se caracteriza mais por um estilo de vida, associado a uma nova ordem econômica, do que um determinado momento histórico ${ }^{1}$. Por esse motivo, Jameson relata que há certa resistência quanto à aceitação e compreensão do "conceito" de pós-moderno.

Dentre suas características pode-se citar um posicionamento de reação ao alto modernismo e a abolição de fronteiras entre a alta cultura e a cultura de massa ou popular ${ }^{2}$. Além destas, outro traço marcante no pós-moderno é a "falência do novo" ou o fim do "fetichismo da genialidade". Nesse sentido, a figura do sujeito enquanto indivíduo único, identitário e singular entrou, igualmente, em declínio reforçando a ideia de que o individualismo passou ou que, até mesmo, nunca chegou a existir 3 . Da mesma forma, a autonomia artística é abalada, pois a arte perde sua posição de

${ }^{1}$ Apesar dessa afirmação, Jameson coloca que o surgimento do pós-modernismo aponta para o fim da Segunda Guerra Mundial (1945), associado ao capitalismo tardio.

${ }^{2}$ No Brasil, um posicionamento semelhante se deu com o movimento Armorial, iniciado em 19 de outubro de 1970. Uma iniciativa artística cujo objetivo seria criar uma arte erudita, a partir de elementos da cultura popular do Nordeste do país. Um dos fundadores e diretores foi o escritor Ariano Suassuna. Tal movimento reúne diversas formas de expressões artísticas como: música, dança, literatura, artes plásticas, teatro, cinema e arquitetura. 
privilégio na pós-modernidade, o que irá reverberar decisivamente nos rumos das linguagens cênicas.

A partir do momento em que o pós-modernismo passa a influenciar o estilo de vida, segundo Jameson (2006), vê-se a ampliação da consciência de uma nova classe que transcende os limites dos grupos fechados (guetos, nichos). Conforme o autor, tal transcendência dos limites atingiu, igualmente, o que se entendia por rural e urbano, por exemplo, não estando mais os mesmos dissociados havendo, portanto, uma mercantilização da área rural e uma capitalização da agricultura. Característica que reforça outro ponto proposto por Jameson (2006) quando afirma que a pósmodernidade não se inicia do aniquilamento da alta modernidade, pois representa uma reconfiguração de seus parâmetros vigentes. Diante de tais transformações, Jameson (2006) aponta que a área da cultura também passou por mudanças que implicaram, principalmente, no seu vínculo com o mercado. Com o advento do consumo como prática cultural, o pós-moderno ressalta a noção de mercantilização da cultura, transformando o cultural em econômico e o econômico em muitas formas de cultura.

\section{A contaminação}

Diante da breve contextualização exposta e, levando em consideração os traços apresentados acerca do pensamento pós-moderno, é válido questionar: nos termos das artes cênicas contemporâneas, em que medida artista e audiência estão compartilhando suas inquietações? Percebe-se um amontoado conceitual, reflexo da prática tanto acadêmica quanto informal dos coletivos teatrais e de performance que buscam produzir conhecimento, a partir de seus olhares sobre as práticas. Entretanto, observa-se que a confusão de conceitos acaba por revelar uma tentativa, que se mostra frustrada, de "encaixotar" as práticas contemporâneas nos compartimentos das linguagens reconhecidas ou legitimadas. Nesse sentido, arrisca-se questionar se tal prática não seria fruto de um problema estrutural, cujas formas de pensar são afetadas, ainda, atualmente, pelas bases da prática pedagógica.

No campo da performance, tal problemática é revisitada através da resistência, cujas expressões enfrentam os padrões de uso do tempo, do espaço e do corpo ${ }^{4}$. A performance, segundo Carlson (2010), pode ser vista como um fenômeno complexo, conflituoso e mutável, configurando-se como uma antidisciplina, resistindo a conclusões, definições, fronteiras e limites. Inserida, assim como o teatro contemporâneo, num campo de difícil delimitação a performance estabelece tensões com a estrutura de pensamento da normatividade, criando espaços de conflito para o artista, o público e a crítica.

\footnotetext{
${ }^{3}$ Para Brito (2012, p. 06), "A filosofia contemporânea de Deleuze e Guattari não cessa de denunciar a desfiguração do sujeito unificado, estável, totalizante e universal. O sujeito unificante e estável está em diluição, o eu está em dissolução. Importa pensar uma subjetividade descentrada, múltipla, nômade, que dialoga com a superfície e não com o fundamento. A filosofia contemporânea desses autores busca romper com a imagem do sujeito universal para pensar uma subjetividade construída na imanência, com a vida e com suas forças, agora não mais substância, fundamento, mas superfície, fluxos de vida, singularidade".

4 "É importante enfatizar que a noção de performance como a conhecemos hoje aparece por volta dos anos 1960, quando inúmeras manifestações artísticas - que não podiam ser classificadas como teatro, dança, pintura, escultura ou qualquer outro gênero previamente conhecido - começam a acontecer simultaneamente pelo mundo afora. A estratégia da performance é resistir a definições. Ela trata justamente de desnortear classificações, de desconstruir modos tradicionais de produção e recepção artística". (FABIÃO, 2009, p. 01)
} 
Com base nas premissas da performance, uma provocação se faz pertinente: ainda podemos ter fronteiras bem definidas entre linguagens artísticas ou esse é um mecanismo de "sobrevivência" utilizado pelos artistas frente ao sistema? Lehmann (2013, p. 874-875) insiste na improdutividade da discussão sobre as definições, para o autor:

É óbvio que o teatro, assim como outras práticas artísticas avançadas, adotou elementos da performance (autorreferencialidade, desconstrução de significado, exposição do mecanismo interno do seu próprio funcionamento, mudança da atuação teatral para a performática, questionamento da estrutura básica da subjetividade, repúdio - ou pelo menos crítica e exposição da representação - e iterabilidade), enquanto a performance, inversamente, se tornou teatralizada de muitas maneiras.

O aspecto da contaminação é recorrente na cena artística contemporânea, chegando a refletir, inclusive, uma crise identitária das linguagens, abalando suas convicções epistemológicas. Nesse sentido, segundo Fernandes (2011, p. 11), atualmente seria adequado falar em "experiências cênicas com demarcações fluidas de território, em que o embaralhamento dos modos espetaculares e a perda de fronteiras entre os diferentes domínios artísticos são uma constante". Para a autora, ainda, é importante pensar no espetáculo como evento que envolve performers e espectadores numa atmosfera única, compartilhada, criando um espaço gerador de experiência que vai além do simbólico. Pode-se dizer que esse ato transgressor da cena contemporânea é capaz de reverberar fisicamente em seus participantes, de modo a criar um ambiente de "infecção emocional".

Ainda sobre tais fronteiras tênues, Fischer-Lichte (2008) aponta o "desvio performativo" sofrido pelo teatro a partir dos anos 1960, cujo redirecionamento não concebe mais o teatro como representação de um mundo ficcional que o público deveria observar, interpretar e compreender. Para Fernandes (2011, p. 17), "a performatividade elude o escopo da teoria estética tradicional, pois resiste às demandas da hermenêutica de compreender a obra de arte", ou seja, a participação do público ultrapassa a missão de interpretar e produzir significado frente a uma performance. $E$ "isso não quer dizer que, numa performance, não haja nada para o espectador interpretar, mas também não se pode dizer que as ações do artista performativo apenas signifiquem alguma coisa" (FERNANDES, 2011, p. 17).

A partir das considerações feitas sobre o teatro/performance contemporâneos pode-se verificar que o papel do espectador se amplia, pois assume uma posição de observador que é, ao mesmo tempo, atuante e sujeito da fruição. Além disso, os espaços da subjetividade são incorporados à ação da recepção, visto que o "contemplar" foi redefinido como atividade, "como um fazer, de acordo com os seus padrões particulares de percepção, com as suas associações e memórias e com os discursos dos quais tivessem participado" (FISCHER-LICHTE, 1988, p. 149).

\section{A fatalidade da produção de sentido e a resistência produtiva}


Segundo o professor e filósofo Charles Feitosa, há que se diferenciar os conceitos de revolução, revolta e resistência. Para o autor, valendo-se de Hannah Aren$\mathrm{dt}$, a revolução no sentido moderno "não envolve simplesmente mudanças, mas sim acontecimentos que pretendem instaurar um novo começo" (FEITOSA, 2007, p. 19). A revolta, por sua vez, é um termo cujo caráter negativo indica "rejeição da autoridade, oposição a um poder, desvio de uma crença (...) dizer não a todo custo, contra tudo e contra todos" (FEITOSA, 2007, p. 22). Já a resistência, cujos estudos de Nietzsche e Deleuze são referências principais,

tem um outro significado para a palavra resistir, que não seja mais um resistir contra algo, mas um re-insistir. Resistência como uma forma especial de enfrentar o poder, de dizer não e sim, de agir conforme a liberdade, de lidar com a morte e com os muros da política (FEITOSA, 2007, p. 26).

Produzir/extrair/atribuir sentido, interpretar e decifrar são termos inevitáveis de serem utilizados nos discursos, e, aqui, chama-se atenção especial para o acontecimento cênico em sua capacidade máxima de encontro com o outro. Qualquer que seja a interação proposta pelo artista, num recorte de espaço e tempo ${ }^{5}$, o encontro com o outro abre múltiplas possibilidades de percepção que, fatalmente, passarão em algum momento pela produção de sentido. $O$ estudo do teórico literário Hans -Ulrich Gumbrecht (2010) percorre caminhos que atravessam essa discussão, a partir do momento em que o autor critica a vocação hermenêutica absoluta assumida com a modernidade. Seu objetivo não é postular o extermínio da interpretação, mas buscar outros meios de contactar as coisas que "estando à nossa frente, ocupam espaço, são tangíveis aos nossos corpos e não são apreensíveis, exclusiva e necessariamente, por uma relação de sentido" (JASMIN, 2010, p. 9).

A performance e o teatro contemporâneo buscam, nesse sentido, o sujeito percipiente cujos níveis de expectação se aproximam mais do sinestésico do que semiótico. Para tanto, os artistas experimentam diversas formas de lidar com o texto literário, - onde não há fechamento da significação - com as imagens e sons produzidos. A partir daí, a gama de efeitos produzidos pelo poético gerado em cada "leitor", como entende Paul Zumthor, "é única, fugaz, irreversível e individual, porque se pode duvidar que a mesma performance seja vivida de maneira idêntica por dois ouvintes" (1997, p. 241).

Ao pressupor que as artes cênicas contemporâneas assumem o desvio performativo, mencionado por Fischer-Lichte, como norte da situação, é válido questionar se o discurso do "deixar-se experimentar sinestesicamente" como prioridade se sustenta, principalmente no que diz respeito ao lugar do público. Outros questionamentos reforçam a reflexão: "Em que medida estas ações afetam a percepção estética e operam 'regras culturais' válidas? Quantos atos como estes transformam os espectadores em performers eles próprios?" (SOARES, 2008, p. 02). Desgranges (2010, p. 50) complementa: "como compreender a pertinência de uma proposta artística que convida o espectador a disponibilizar-se para um modo de leitura que ultrapasse a

${ }^{5}$ Por exemplo: uma manifestação ao vivo ou o registro de uma performance cuja duração foi de um ano/um dia, exposto numa galeria ou projetado num espaço da cidade. 
barreira da dimensão lógico-racional, e se permita saborear os descaminhos da experiência com a arte?".

A arte assume, então, o lugar das brechas e lacunas, buscando irromper no caos momentos em que o consciente seja surpreendido, pego desatento. Nesse contexto, para Desgranges (2010, p. 55), "o estímulo cotidiano frequente a uma atuação hiperbólica da consciência deixa a psique pouco disponível para a percepção sensível, que ultrapasse o mecanismo meramente instrumental". Segundo o autor, "as alterações na percepção solicitam procedimentos artísticos modificados para provocar a irrupção da memória involuntária". Portanto, o teatro e a performance no contexto contemporâneo atuam para sugerir ao indivíduo novas formas de vivenciar o espaço e o tempo, para apresentar possibilidades do "se perder", colocar-se num risco não -habitual, explorar o poético como desconhecido, contrapondo o sujeito ao modo usual e operacional de "ver, sentir e pensar o mundo".

Considerando a inevitabilidade da produção de sentido e, simultaneamente, a busca pelo contato mais presencial com as coisas e os acontecimentos, chega-se ao impasse do contemporâneo, o qual produtores e sujeitos da fruição compartilham. Nesse sentido, dentre os conceitos trazidos por Feitosa (2007), é pertinente destacar a resistência como uma noção geradora de novas perspectivas. Sendo assim, pensar sobre o "re-insistir" nos papéis de artista e público é válido se encararmos tal movimento como um modo de fazer as discordâncias e divergências tornarem-se produtivas para os momentos de criação/recepção.

\section{Os lugares do público}

Quais são os lugares do público na cena contemporânea e quais grupos sociais ou comunidades definem, majoritariamente, tal entidade? Tais questionamentos tomam como ponto de partida as propostas cênicas atuais, cuja participação do espectador é valorizada, mesmo que nem sempre aconteça de forma ativa. Nesse campo prático observa-se certo declínio da recepção contemplativa, em detrimento de outros modos de percepção que buscam incluir a contaminação como tendência. Segundo o professor e pesquisador Flávio Desgranges, ao contextualizar esse novo olhar, detalhado por Benjamin acerca de um quadro do pintor Cézanne,

[...] esse modo de recepção se efetiva de modo inverso ao da recepção contemplativa, pois, em vez de convidar o espectador a mergulhar na estrutura interna da obra, faz imergir o objeto artístico no espectador, atingindo-o organicamente, o que sustenta a noção tátil desse modo receptivo. O objeto como que avança sobre o indivíduo, toca-lhe o íntimo de maneira inesperada [...] (DESGRANGES, 2012, p. 123).

Ainda sobre a autonomia conferida ao espectador:

O tempo vazio se abre diante do espectador como a página em branco de um novo texto, que somente a ele cabe escrever. Tal como os atores em processo de criação, o público é colocado numa situação de improviso, em que, em diálogo com as propostas cênicas, é lançado (e se lança) em corrente de invenções potenciais, 
naquele estado de flow em que a gente se descobre espectador das próprias ações (DESGRANGES, 2012, p. 128).

Para o ensaísta e crítico de arte francês Nicolas Bourriaud, a arte contemporânea e sua produção estão intrinsecamente ligadas pelas relações que estabelecem com o público, a este raciocínio o autor chama de "arte relacional". Seu princípio é claro: é relacional, pois só pode se compor com o outro. Sua consequência parece, igualmente, evidente, ou seja, não me defino mais pelo que sou, mas pelas relações que tenho, podendo estender-se ao status da obra de arte que também não se define mais pelo que se intitula - teatro, dança ou performance -, mas pelas relações que consegue estabelecer com seu espectador.

Segundo Camilletti (2010), Bourriaud entende a forma relacional como a esfera das interações humanas em lugar do espaço privado e autônomo. O autor acrescenta que "o relacional implica uma instância de elaboração conjunta, na qual a decisão do espectador (que já não o é mais, de certa forma) afete a discursividade do artista ". Nesse sentido, fica clara a pertinência do conceito, já que o mesmo subverte o posicionamento dual do espectador ativo-passivo e o coloca num espaço vazio, porém de pró-atividade, entre as duas atitudes. Ainda sobre este papel que o público assume, cujo sujeito não mais apenas observa o acontecimento artístico, mas o realiza em conjunto com o artista, pode-se questionar: em que medida o espectador ainda pode assegurar seu lugar na crítica, já que o mesmo passa a ser produtor e parte integrante da obra?

\section{Contaminação como potência: territórios, desterritórios e reter- ritórios}

A ideia de contaminação como potência surge do posicionamento que reconhece na cena contemporânea a impossibilidade de segmentação das linguagens. Nesse sentido, trata-se de agregar à discussão em andamento a seguinte questão: como os processos de contaminação da cena contemporânea podem potencializar a relação com o espectador? E ainda: em que medida essa potência é capaz de movimentar ou desestabilizar o espectador de modo que o mesmo transite pelos possíveis territórios?

O conceito de território se relaciona com todo universo que abarca a construção da subjetividade, os padrões, espaços de convívio, gostos e projetos de um indivíduo. Em O vocabulário de Deleuze, Zourabichvili (2004, p. 23) afirma que "o conceito de território decerto implica o espaço, mas não consiste na delimitação objetiva de um lugar geográfico. Seu valor é existencial: ele circunscreve o campo do familiar e do vinculante, marca as distâncias em relação a outrem e protege do caos". A noção de território percorre, igualmente, outros três conceitos que se complementam e atingem níveis além dos estudos acerca das culturas e seus comportamentos, estes são: territorialidade, desterritorialização e reterritorialização. Ainda sobre o território, pode-se acrescentar: 
O território pode abarcar tanto um espaço vivido quanto um sistema dentro do qual um "sujeito" se sente em casa. Ele é sinônimo de apropriação, de subjetivação fechada sobre si mesma, o conjunto dos projetos e representações nos quais desemboca, pragmaticamente, toda uma série de comportamentos, investimentos, nos tempos e espaços sociais, culturais, estéticos e cognitivos .

A partir das colocações feitas, pode-se observar que cada "sujeito" tem intimamente a delimitação do seu território. Nesse sentido, cabe perguntar: quando é que o espectador na performance e no teatro contemporâneo passa por processos de territorialização, desterritorialização e reterritorialização? Ao buscar em experiências recentes de recepção fatos que possam "exemplificar" tais problematizações, chegase à performance "Bivouac" do grupo francês Genérik Vapeur .

O espetáculo, que tem duração de 60 minutos, percorreu 600 metros do bairro Cidade Baixa em Porto Alegre, atravessando avenidas de grande fluxo, interrompendo a ordem do trânsito dos carros e pedestres. O percurso foi sendo delimitado através da movimentação dos barris conduzidos pelos performers em associação ao carro elétrico que se mantinha na parte de trás do "cortejo". Dois aspectos que caracterizam essa performance ficam claros no momento da recepção: a itinerância e a contaminação. Ambos estão intimamente ligados em Bivouac, não apenas pelo fato do grupo deixar claro seu desejo em termos estéticos, mas pela potência de envolvimento que tais escolhas transparecem. A itinerância é marcante na participação do espectador, pois o leva a questionamentos como: Por que eu estou fazendo este trajeto e o que me leva a correr atrás dessas pessoas? Há uma espécie de condução que não é guiada, de forma explícita, mas deixa claro um tipo de abordagem, cujo participante se sente convidado e parte integrante do acontecimento. Em Bivouac materializa-se o resgate do sujeito percipiente e intensifica-se o estímulo à produção de presença, tal como propõe Gumbrecht (2010).

A partir dessa experiência, alguns fenômenos como a perda da sensação de tempo e espaço podem ser pensados como característicos da potência da contaminação na cena. O espectador na contemporaneidade, condutor e conduzido, contemplado e contemplante, transita pelo seu arcabouço de associações (des)conhecidas gerando, assim, idas e vindas pelos territórios circundantes. Sobre a ação de "deixar o território" Zourabichvili (2004, p. 24) problematiza: "que relação com o estranho, que proximidade do caos suporta o território? Qual é seu grau de fechamento ou, ao contrário, de permeabilidade (crivo) ao fora (linhas de fuga, pontas de desterritorialização)? Nem todos os territórios se equivalem, e sua relação com a desterritorialização, como vemos, não é de simples oposição".

Apontar a complexidade do trânsito entre territórios é um exercício necessário para pensar e repensar as relações estabelecidas atualmente com o espectador. Externalizar a lógica dos bons encontros, torna-la presente, tangível e potencializar a coletividade no sentido de produzi-la. A lógica da resistência proposta por Feitosa (2007), baseada no insistir novamente, assume papel fundamental no fazer/fruir do teatro/performance contemporâneos. Nesse sentido, o lugar de propositor no qual o público é incentivado a estar não se dá através de um movimento revolucionário ou de revolta, porque busca mais uma reestruturação das configurações padrão, do que 
uma nova ordem, respondendo, igualmente, à tendência da pós-modernidade em relação à alta modernidade.

\section{Referências}

BRITO, Maria dos Remédios de. Dialogando com Gilles Deleuze e Félix Guattari sobre a ideia de Subjetividade Desterritorializada. Alegrar, [s.l.], v. 9, p.6, jun. 2012. Disponível em: http://www.alegrar.com.br/revista09/pdf/dialogando_com_gilles_maria_brito_alegrar9.pdf. Acesso em: 24 jul. 2014.

CAMILLETTI, Gerardo. La dimensión política de lo relacional. Territorio Teatral. Buenos Aires, 2010. Semestral. Disponível em: http://territorioteatral.org.ar/ html.2/dossier/n6_01.html. Acesso em: 20 jul. 2014.

CARLSON, Marvin. Performance: uma introdução crítica. Belo Horizonte: Editora UFMG, 2010, $284 \mathrm{p}$.

DESGRANGES, Flávio. Arte como experiência da arte. Lamparina: Revista de ensino de teatro, Belo Horizonte, v. 1, n. 1, p.50-56, jun. 2010.

A inversão da olhadela: alterações no ato do espectador teatral. São Paulo: Hucitec, 2012, 228 p.

FABIÃO, Eleonora. Definir performance é um falso problema. Caderno 3, Diário do Nordeste. 09 de jul. 2009. Entrevista a Fábio Freire. Disponível em: http://diariodonordeste.verdesmares.com.br/cadernos/caderno-3/definir-performance -e-um-falso-problema-1.281367. Acesso em: 15 jul. 2014.

FEITOSA, Charles. Revolução, revolta e resistência: a sabedoria dos surfistas. In: LINS, Daniel (Org.). Nietzsche, Deleuze, arte, resistência. Rio de Janeiro: Forense Universitária; Fortaleza: Fundação de Cultura, Esportes e Turismo, 2007. p. 1731.

FERNANDES, Sílvia. Teatralidade e Performatividade na cena contemporânea. Repertório, Salvador, v. 1, n. 16, p.11-23, jun. 2011. Semestral.

FISCHER-LICHTE, Erika. Perfomance e Cultura Performativa, Revista de Comunicação e Linguagens, Edições Cosmos, Lisboa, 1988.

The transformative power of performance. London and New York, Routledge, 2008. 
GUMBRECHT, Hans-Ulrich. Produção de presença: o que o sentido não consegue transmitir. Tradução: Ana Isabel Soares. Rio de Janeiro: Contraponto: Ed. PUC-Rio, 2010.

JAMESON, Fredric. A virada cultural: reflexões sobre o pós-moderno. Civilização Brasileira. Rio de Janeiro. 2006.

JASMIN, Marcelo. Efeitos de uma intensa presença. In: GUMBRECHT, Hans-ulrich. Produção de presença: o que o sentido não consegue transmitir. Rio de Janeiro: Contraponto, 2010. p. 7-12.

LEHMANN, Hans-thies. Teatro Pós-dramático, doze anos depois. Revista Brasileira de Estudos da Presença, Porto Alegre, v. 3, n. 3, p.859-878, set. 2013. Semestral.

PAVIS, Patrice. A encenação contemporânea: origens, tendências, perspectivas. Tradução de Nanci Fernandes. São Paulo: Perspectiva, 2010, 433 p.

SOARES, Luiz Claudio Cajaíba. Algumas reflexões sobre os modos de recepção das Artes Cênicas contemporaneamente. 2008. Disponível em: http://portalabrace.org/memoria/vcongressoteorias.htm. Acesso em: 02 jul. 2014.

ZOURABICHVILI, François. O vocabulário de Deleuze. Tradução de André Telles. Rio de Janeiro: EDIOURO - SINGULAR, 2004, 66 p.

ZUMTHOR, P. Introdução à poesia oral. Tradução de Jerusa Pires Ferreira, Maria Lúcia Diniz Pochat e Maria Inês de Almeida. São Paulo: Hucitec, 1997. 